\title{
Perlindungan hukum terhadap pasien BPJS Kesehatan dalam mendapatkan pelayanan kesehatan di RSUD dr. Doris Sylvanus Palangka Raya
}

\section{Legal protection for Health BPJS patients in obtaining health services at RSUD dr. Doris Sylvanus Palangka Raya}

\author{
Yulius Don Pratama ${ }^{1, *}$, Sangking ${ }^{2}$, Thea Farina ${ }^{2}$ \\ ${ }^{1}$ Badan Pengelola Keuangan dan Aset Daerah Kabupaten Kapuas \\ 2 Program Studi Magister Ilmu Hukum Program Pascasarjana Universitas Palangka Raya. Kampus UPR Tunjung Nyaho, \\ Jl. Yos Sudarso Palangka Raya, Indonesia, 73111 \\ * Korespondensi: Yulius Don Pratama (Email: iuzpratama@gmail.com)
}

https://e-journal.upr.ac.id/index.php/jem

Received: 13 April 2021 https://doi.org/10.37304/jem.v2i2.2948

Accepted: 25 May 2021

\begin{abstract}
The National Health Insurance Program-Healthy Indonesia Card (JKN-KIS) organized by the Health Social Security Administration (BPJS Kesehatan) is a government program that aims to improve the health status of the community. This study examines the implementation of legal protection for patients participating in JKN-KIS BPJS Health in obtaining health services at hospitals. The aspects studied include health service procedures, settlement of complaints, and barriers to the implementation of protection for JKN-KIS BPJS Health patients at dr Doris Sylvanus Hospital, Palangka Raya. The research is descriptive qualitative, using empirical legal research methods. Data were collected from literature, legislation on JKN-KIS BPJS Health, secondary data from BPJS Health, RSUD dr. Doris Sylvanus Palangka Raya and patients participating in the JKN-KIS. Based on the research, it was concluded that the implementation of legal protection for $J K N-K I S$ BPJS Health participants at RSUD dr. Doris Sylvanus is categorized as good. This is evidenced by the fulfillment of information regarding hospital rules and regulations, information on patient rights and obligations, information on diagnosis and procedures for medical actions from health workers, security and safety guarantees while in hospital and a place for handling patient complaints/complaints provided. the hospital. Barriers to the implementation of protection for patients participating in JKN-KIS BPJS Health at Dr Doris Sylvanus Hospital are the presence of patients who do not pay dues, patients participating in JKN-KIS do not know the BPJS Health service procedures, the standard waiting time to get health services is relatively long, and the unavailability of some sub-systems. medical specialist in hospital.
\end{abstract}

\section{Keywords}

Protection of rights, patients, JKN-KIS, health services

\section{Intisari}

Program Jaminan Kesehatan Nasional-Kartu Indonesia Sehat (JKN-KIS) yang diselenggarakan oleh Badan Penyelenggara Jaminan Sosial Kesehatan (BPJS Kesehatan) merupakan program pemerintah yang bertujuan untuk meningkatkan derajat kesehatan masyarakat. Penelitian ini mengkaji pelaksanaan perlindungan hukum terhadap pasien peserta JKN-KIS BPJS Kesehatan dalam mendapatkan pelayanan kesehatan di rumah sakit. Aspek yang dikaji meliputi prosedur pelayanan kesehatan, penyelesaian pengaduan/keluhan, dan hambatan pelaksanaan perlindungan terhadap pasien JKN-KIS BPJS Kesehatan di RSUD dr Doris Sylvanus Palangka Raya. Penelitian bersifat deskriptif kualitatif, menggunakan metode penelitian hukum empiris. Data dikumpulkan dari literature, peraturan perundangundangan tentang JKN-KIS BPJS Kesehatan, data sekunder dari BPJS Kesehatan dan RSUD dr. Doris Sylvanus Palangka Raya serta pasien peserta JKN-KIS. Berdasarkan penelitian disimpulkan bahwa pelaksanaan perlindungan hukum terhadap pasien peserta JKN-KIS BPJS Kesehatan di RSUD dr. Doris Sylvanus dikategorikan baik. Hal ini dibuktikan dengan terpenuhinya informasi mengenai tata tertib dan peraturan di rumah sakit, informasi hak dan kewajiban pasien, informasi diagnosis dan tatacara tindakan medis dari tenaga kesehatan, adanya jaminan keamanan dan keselamatan selama di rumah sakit serta adanya tempat penanganan pengaduan/keluhan pasien yang disediakan pihak rumah sakit. Hambatan pelaksanaan perlindungan terhadap pasien peserta JKN-KIS BPJS Kesehatan 
di RSUD dr Doris Sylvanus adalah adanya pasien yang tidak membayar iuran, pasien peserta JKN-KIS tidak mengetahui prosedur pelayanan BPJS Kesehatan, standar waktu tunggu mendapatkan pelayanan kesehatan relatif lama, dan belum tersedianya sebagian sub spesialis tenaga kesehatan di rumah sakit.

Kata kunci

Pelindungan hak, pasien, JKN-KIS, pelayanan kesehatan

\section{PENDAHULUAN}

Kesehatan adalah salah satu kebutuhan pokok manusia, tanpa hidup yang sehat manusia akan mengalami sakit, sehingga tidak dapat melakukan kegiatan sehari-hari dengan baik. Orang yang sedang sakit akan meminta pertolongan dari tenaga kesehatan dan tenaga kesehatan akan memberikan pelayanan kesehatan (Ainsyiyah et al., 2015). Cita-cita bangsa Indonesia yang tercantum di dalam Undang Undang Dasar Negara Republik Indonesia Tahun 1945, yaitu melindungi segenap bangsa Indonesia dan seluruh tumpah darah Indonesia dan memajukan kesejahteraan umum, mencerdaskan kehidupan bangsa dan ikut melaksanakan ketertiban dunia yang berdasarkan kemerdekaan, perdamaian abadi, dan keadilan sosial. Ditegaskan kembali pada pasal $28 \mathrm{H}$ ayat (1), yang berbunyi:

"Setiap orang berhak hidup sejahtera lahir dan batin, bertempat tinggal dan mendapatkan lingkungan hidup yang baik dan sehat serta berhak memperoleh pelayanan kesehatan".

Pasal tersebut menjelaskan bahwa kesehatan merupakan hak asasi atau hak dasar setiap orang yang dijamin oleh negara. Pembangunan kesehatan merupakan bagian dari pembangunan nasional, dalam pembangunan kesehatan tujuan yang ingin dicapai adalah meningkatkan derajat kesehatan masyarakat yang optimal (Setyawan, 2018).

Keseriusan dan perhatian pemerintah terhadap pembangunan kesehatan ini menguat dengan menempatkan jaminan kesehatan sebagai perlindungan sosial pada UUD 1945 pasal 34 ayat (2), yaitu menyebutkan bahwa:

"Negara mengembangkan sistem jaminan sosial bagi seluruh rakyat Indonesia".

Negara juga berkewajiban menjamin kesehatan warga negaranya, sebagaimana yang tercantum dalam pasal 34 ayat (3) UUD RI 1945 yang berbunyi:

"Negara bertanggung jawab atas penyediaan fasilitas pelayanan kesehatan dan fasilitas pelayanan umum yang layak."

Pemerintah Indonesia menetapkan Undang-Undang Nomor 40 Tahun 2004 tentang Sistem Jaminan Sosial Nasional (SJSN) sebagai bukti bahwa pemerintah memiliki komitmen yang besar untuk mewujudkan kesejahteraan sosial bagi seluruh rakyatnya. Atas dasar itu dibentuklah PT. Askes (Persero) sebagai badan penyelenggara jaminan kesehatan bagi Pegawai Negara Sipil (PNS) sekaligus pelaksana program Jamkesmas.

Pada 1 Januari 2014 PT. Askes (Persero) berubah menjadi Badan Penyelenggara Jaminan Sosial Kesehatan (BPJS). Dengan perubahan ini maka seluruh program PT. Askes (Persero) sebagai penyelenggara jaminan sosial dan sebagai pelaksana program Jamkesmas beralih ke BPJS Kesehatan sesuai Undang-Undang Nomor 24 Tahun 2011 tentang BPJS.

BPJS Kesehatan adalah badan hukum yang dibentuk untuk menyelenggarakan program jaminan kesehatan. Jaminan kesehatan adalah jaminan berupa perlindungan kesehatan agar peserta memperoleh manfaat pemeliharaan kesehatan dan perlindungan dalam memenuhi kebutuhan dasar kesehatan yang diberikan kepada setiap orang yang telah membayar iuran atau iurannya dibayar oleh pemerintah. Sehingga tercipta mekanisme subsidi silang dan gotong royong masyarakat dalam jaminan kesehatan yang berdasarkan pada sistem jaminan sosial yang berbasis asuransi sosial (Dewi, 2020).

BPJS Kesehatan mempunyai tugas utama yaitu menyelenggarakan Jaminan Kesehatan Nasional (JKN) bagi warga negara Indonesia. Pelayanan kesehatan yang dijamin oleh BPJS mencakup pelayanan promotif, preventif, kuratif, dan rehabilitatif termasuk pelayanan obat dan bahan medis habis pakai sesuai kebutuhan medis yang diperlukan (Nanda dan Aminah, 2016). Program JKN-KIS BPJS Kesehatan merupakan program Pemerintah Indonesia dalam mewujudkan upaya memberi pelayanan kesehatan secara menyeluruh kepada penduduk Indonesia agar dapat merasakan manfaat jaminan kesehatan yang berguna untuk pemeliharaan kesehatan dan perlindungan dalam memenuhi kebutuhan dasar kesehatan (Jabbar, 2020).

Program JKN, BPJS Kesehatan bekerjasama dengan badan-badan penyedia pelayanan kesehatan sebagai mitra dalam melayani peserta BPJS seperti rumah sakit pemerintah maupun swasta, klinik-klinik kesehatan, praktek dokter, apotek, serta optik, dan lainnya. Dalam perikatan kerjasama kemitraan tersebut dituangkan dalam naskah perjanjian dalam bentuk Nota Kesepahaman (Memorandum of Understanding-MoU) yang mengatur hak dan kewajiban antar masing-masing pihak terdapat hubungan hukum antara BPJS selaku badan hukum publik menjadi wadah yang menghimpun seluruh kegiatan yang 
berhubungan dengan jaminan sosial dalam hal ini khususnya jaminan kesehatan di Indonesia.Pelayanan kesehatan pada sistem BPJS Kesehatan di rumah sakit terbagi menjadi beberapa kelas ruang perawatan, yaitu kelas I, kelas II, kelas III yang sesuai dengan jenis kepesertaan dari anggota BPJS Kesehatan. Peserta Penerima Bantuan luran (PBI) hanya di kelas III sedangkan non $\mathrm{PBI}$ dapat memilih sesuai dengan pilihannya (Suprianto dan Mutiarin, 2017).

Keberadaan rumah sakit merupakan sarana yang wajib disediakan pemerintah sebagai wujud kepedulian terhadap kesehatan masyarakatnya. Rumah sakit sebagai tempat pelayanan kesehatan dituntut untuk memberikan pelayanan yang bermutu sesuai dengan standar yang ditetapkan dan merupakan bagian dari sumber daya kesehatan yang sangat diperlukan dalam mendukung penyelenggaraan upaya kesehatan (Susila, 2014). Namun dalam proses pelaksanaannya, program JKN bagi masyarakat di Indonesia masih belum optimal. Salah satu contoh permasalahan yang dihadapi oleh pasien BPJS kesehatan yaitu ketersediaan kamar yang terkadang penuh, kelas ruangan yang tidak sesuai dan kurang maksimalnya pelayanan kesehatan yang diberikan oleh rumah sakit kepada pasien BPJS Kesehatan (Mulia, 2017). Dokter dan perawat sebagai tenaga kesehatan palingdekat hubungannya dengan pasien dalam penanganan penyakit. Terdapat beberapa hubungan dalam upaya pelayanan kesehatan tersebut, yaitu hubungan antara rumah sakit dengan tenaga kesehatan serta pasien dengan tenaga kesehatan itu sendiri (Muninjaya, 2004).

BPJS Kesehatan dalam melaksanakan program jaminan kesehatan nasional perlu memperhatikan beberapa hal guna tercapainya keberhasilan upaya pembangunan dalam bidang kesehatan tersebut. Salah satunya ialah ketersediaan yang berupa tenaga, sarana, dan prasarana dalam jumlah mutu yang memadai. Dalam rangka menunjang terwujudnya pelayanan kesehatan yang baik dan optimal, pemerintah menetapkan berlakunya standar pelayanan medis di rumah sakit dan standar pelayanan rumah sakit. Standar pelayanan medis tersebut merupakan sendi utama dalam upaya peningkatan mutu pelayanan medis di Indonesia (Soekidjo, 2010). Standar pelayanan medis ini merupakan hukum yang mengikat para pihak yang berprofesi di bidang kesehatan, yaitu untuk mengatur pelayanan kesehatan dan untuk mencegah terjadinya kelalaian staf medis dalam melakukan tindakan medis.

Rumah Sakit Umum Daerah (RSUD) dr. Doris Sylvanus merupakan rumah sakit tipe $B$ milik Pemerintah Provinsi Kalimantan Tengah dengan alamat jalan Tambun Bungai No. 04 Palangka Raya yang telah bekerja sama dengan BPJS Kesehatan dan merupakan fasilitas kesehatan rujukan tingkat lanjutan yang menjadi pusat rujukan dari kabupaten/kota di Kalimantan Tengah. Berdasarkan pada observasi awal di RSUD dr. Doris Sylvanus Palangka Raya terdapat keluhan pelayanan kesehatan dari pasien BPJS Kesehatan karena tidak mendapatkan pelayanan kesehatan sesuai dengan haknya.
Berdasarkan uraian tersebut penelitian ini bertujuan mengetahui pelaksanaan perlindungan hukum terhadap pasien BPJS Kesehatan dalam mendapatkan pelayanan kesehatan di RSUD dr. Doris Sylvanus Palangka Raya berserta kendala-kendala yang dihadapi dalam penyelenggaraannya.

\section{METODOLOGI}

Penelitian ini adalah penelitian yuridis empiris yang mengkaji ketentuan hukum yang berlaku serta apa yang terjadi dalam kenyataannya di masyarakat. Penelitian yang dilakukan terhadap keadaan sebenarnya atau keadaan nyata yang terjadi di masyarakat dengan maksud untuk mengetahui dan menemukan fakta- fakta dan data yang dibutuhkan, setelah data yang dibutuhkan terkumpul kemudian menuju kepada identifikasi masalah yang pada akhirnya menuju pada penyelesaian masalah (Waluyo, 2002). Penelitian ini dilakukan di RSUD dr. Doris Sylvanus Palangka Raya yang beralamat di jalan Tambun Bungai No. 04 Palangka Raya, Kalimantan Tengah. Data dikumpulkan melalui observasi, wawancara, studi kepustakaan, dan dokumentasi. Data kemudian dianalisis secara deskriptif kualitatif, yaitu dengan menelaah apa yang dinyatakan oleh narasumber secara lisan maupun tertulis pada saat mengadakan wawancara dan menyajikannya dalam bentuk ringkas. Data yang diperoleh berdasarkan kenyataan kemudian dikaitkan dengan aturan hukum yang berlaku lalu dibahas, dianalisis, kemudian ditarik kesimpulan dan saran untuk menjawab permasalahan yang diteliti.

\section{HASIL}

\subsection{Pelaksanaan Perlindungan Hukum Terhadap Pasien JKN-KIS Dalam Mendapat Pelayanan Kesehatan di RSUD dr. Doris Sylvanus}

RSUD dr. Doris Sylvanus sebagai rumah sakit umum milik Pemerintah Provinsi Kalimantan Tengah memiliki peran penting dalam pemberian pelayanan kesehatan di Kalimantan Tengah, adanya program JKN-KIS dari BPJS Kesehatan semakin meningkatkan kesadaran masyarakat akan pentingnya kesehatan. Sebagai rumah sakit milik pemerintah, RSUD dr. Doris Sylvanus sejak tahun 2014 secara otomatis menjadi mitra dari BPJS Kesehatan.

Pelaksanaan perlindungan hukum terhadap pasien peserta JKN-KIS dapat dilihat dari pemenuhan hak-hak pasien dalam mendapatkan pelayanan kesehatan di rumah sakit yang harus sesuai dengan peraturan perundanganundangan yang berlaku. RSUD $d r$ Doris Sylvanus memberlakukan perlindungan hak pasien yang tercantum dalam pasal 32 Undang-Undang No. 44 Tahun 2009 tentang Rumah Sakit sesuai dengan SK Direktur RSUD dr. Doris Sylvanus Nomor: 6135.1/KH-HK/RSUD/11-2015, 
yaitu:

a) memperoleh informasi mengenai tata tertib dan peraturan yang berlaku di Rumah Sakit

b) memperoleh informasi tentang hak dan kewajiban pasien

c) memperoleh layanan yang manusiawi, adil, jujur, dan tanpa diskriminasi

d) memperoleh layanan kesehatan yang bermutu sesuai dengan standar profesi dan standar prosedur operasional

e) memperoleh layanan yang efektif dan efisien sehingga pasien terhindar dari kerugian fisik dan materi

f) mengajukan pengaduan atas kualitas pelayanan yang didapatkan

g) memilih dokter dan kelas perawatan sesuai dengan keinginannya dan peraturan yang berlaku di Rumah Sakit

h) meminta konsultasi tentang penyakit yang dideritanya kepada dokter lain yang mempunyai Surat Izin Praktik (SIP) baik di dalam maupun di luar Rumah Sakit

i) mendapatkan privasi dan kerahasiaan penyakit yang diderita termasuk data-data medisnya

j) mendapat informasi yang meliputi diagnosis dan tata cara tindakan medis, tujuan tindakan medis, alternatif tindakan, risiko dan komplikasi yang mungkin terjadi, dan prognosis terhadap tindakan yang dilakukan serta perkiraan biaya pengobatan

k) memberikan persetujuan atau menolak atas tindakan yang akan dilakukan oleh tenaga kesehatan terhadap penyakit yang dideritanya;

I) didampingi keluarganya dalam keadaan kritis

m) menjalankan ibadah sesuai agama atau kepercayaan yang dianutnya selama hal itu tidak mengganggu pasien lainnya

n) memperoleh keamanan dan keselamatan dirinya selama dalam perawatan di Rumah Sakit

o) mengajukan usul, saran, perbaikan atas perlakuan Rumah Sakit terhadap dirinya

p) menolak pelayanan bimbingan rohani yang tidak sesuai dengan agama dan kepercayaan yang dianutnya

q) menggugat dan/atau menuntut Rumah Sakit apabila Rumah Sakit diduga memberikan pelayanan yang tidak sesuai dengan standar baik secara perdata ataupun pidana

r) mengeluhkan pelayanan Rumah Sakit yang tidak sesuai dengan standar pelayanan melalui media cetak dan elektronik sesuai dengan ketentuan peraturan perundang-undangan.

Berdasarkan pada ketentuan di atas, maka pelayanan kesehatan hanya dapat diselenggarakan apabila tenaga kesehatan yang bersangkutan telah memenuhi persyaratan dan perizinan yang diatur dalam Undang-Undang No. 29 Tahun 2004 tentang Praktik Kedokteran, terutama dalam Pasal 29 ayat (1) dan (3) yang antara lain sebagai berikut:

a) Setiap dokter dan dokter gigi yang melakukan praktik kedokteran di Indonesia wajib memiliki surat tanda registrasi dokter dan surat tanda registrasi dokter gigi

b) Untuk memperoleh surat tanda registrasi dokter dan surat tanda registrasi dokter gigi harus memenuhi persyaratan:

1. Memiliki ijazah dokter, dokter spesialis, dokter gigi, atau dokter gigi spesialis

2. Mempunyai surat pernyataan telah mengucapkan sumpah/ janji dokter atau dokter gigi

3. Memiliki surat keterangan sehat fisik dan mental

4. Memiliki sertifikat kompetensi

5. Membuat pernyataan akan mematuhi dan melaksanakan ketentuan etika profesi.

Di samping persyaratan-persyaratan tersebut di atas, dokter atau dokter gigi dalam melakukan pelayanan kesehatan harus pula memiliki izin praktik, sebagaimana ditentukan dalam Pasal 36 Undang-Undang Nomor 29 Tahun 2009 Praktik Kedokteran sebagai berikut: "Setiap dokter dan dokter gigi yang melakukan praktik kedokteran di Indonesia wajib memiliki surat Izin Praktik" (Siswati, 2013).

Dari ketentuan di atas dapat ditafsirkan bahwa, keseluruhan persyaratan tersebut merupakan landasan legalitasnya dokter dan dokter gigi dalam menjalankan pelayanan kesehatan.

Pelayanan kesehatan yang berdaya guna dan berhasil guna hanya dapat tercapai apabilanada keterbukaan dan kesamaan kedudukan dalam hukum antara dokter dan pasien dengan didasarkan pada sikap saling percaya. Sikap tersebut dapat tumbuh apabila dapat terjalin komunikasi secara terbuka antara dokter dan pasien, di mana pasien dapat memperoleh penjelasan dari dokter dalam komunikasi yang transparan (Yustina, 2012).

Pelayanan kesehatan di rumah sakit akan sangat ditentukan oleh ketersediaan fasilitas yang tersedia seperti jenis pelayanan maupun tenaga pelayanan dokter spesialis yang ada. Dalam memberi pelayanan kesehatan, RSUD dr. Doris Sylvanus Palangka Raya didukung oleh tenaga kesehatan dan pekerja lain serta fasilitas medis yang memadai.

RSUD dr. Doris Sylvanus Palangka Raya sebagai rumah sakit kelas B harus mempunyai fasilitas dan kemampuan pelayanan medis sekurang-kurangnya 11 spesialistik dan sub spesialistik terbatas. Jumlah seluruh pegawai yang bekerja di RSUD dr. Doris Sylvanus sampai pada tahun 2018 berjumlah 1.114 pegawai. Berdasarkan dari data jumlah pegawai tersebut dapat diketahui bahwa RSUD dr. Doris Sylvanus memiliki tenaga kesehatan dan pegawai yang cukup lengkap untuk rumah sakit dengan tipe B. Seluruh tenaga kesehatan yang bekerja pada bidang medis diharuskan mempunyai STR (Surat Tanda Registrasi) dan SIP (Surat Tanda Izin) agar dapat melindungi masyarakat atas tindakan yang dilakukan oleh tenaga kesehatan.

Sebuah rumah sakit harus memenuhi, persyaratan teknis sarana dan prasarana rumah sakit untuk menunjang pelayanan kesehatan. Keseluruhan persyaratan tersebut harus direncanakan sesuai dengan standar dan kaidah- 
kaidah yang berlaku. Adapun secara umum yang dimaksud dengan sarana adalah segala sesuatu hal yang menyangkut fisik gedung/ bangunan serta ruangan. Sedangkan prasarana adalah segala sesuatu yang membuat sarana tersebut dapat berfungsi seperti pengadaan air bersih, listrik, instalasi air limbah dan lain-lain (Ginting, 2019).

RSUD dr. Doris Sylvanus termasuk ke dalam kategori Fasilitas Kesehatan Rujukan Tingkat Lanjut (FKRTL) harus melaksanakan prosedur pelayanan pasien JKN-KIS BPJS Kesehatan sesuai dengan Peraturan Menteri Kesehatan Nomor 28 tahun 2014 tentang Pedoman Pelaksanaan Program Jaminan Kesehatan Nasional.

Alur pelaksanaan pelayanan kesehatan pasien rawat jalan peserta JKN-KIS di RSUD dr. Doris Sylvanus disajikan pada Gambar 1 sedangkan untuk pasien rawat inap disajikan pada Gambar 2.

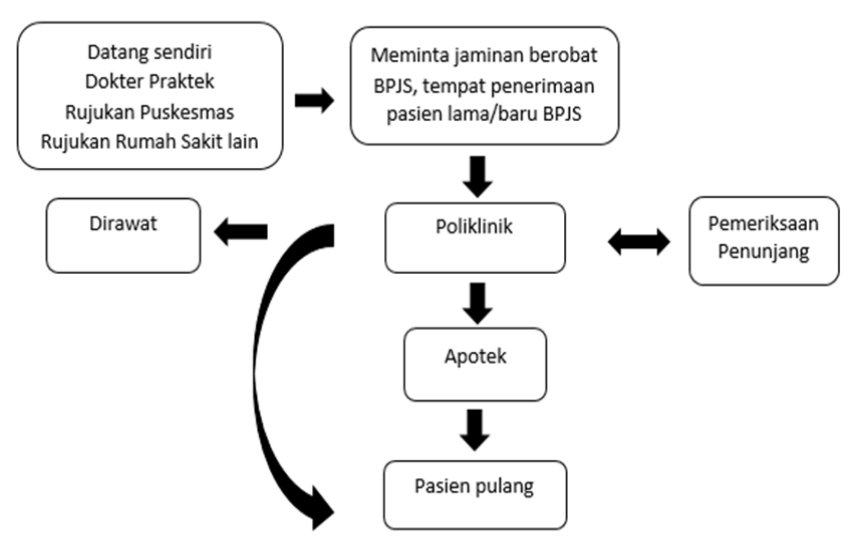

Gambar 1 Alur pelayanan pasien rawat jalan

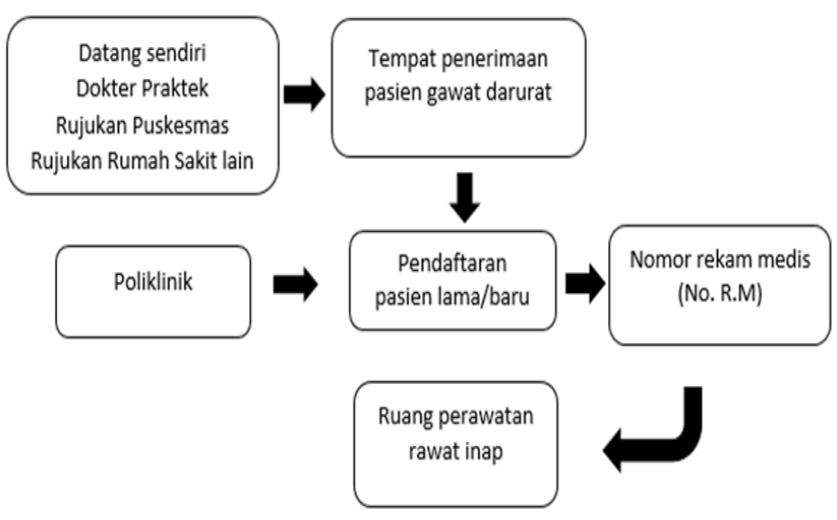

Gambar 2 Alur pelayanan pasien rawat inap

Loket pendaftaran pasien di RSUD dr. Doris Sylvanus dibedakan sebagai berikut:

1. Loket pasien peserta JKN-KIS berjumlah 3 loket.

2. Loket layanan rawat inap berjumlah 1 loket.

3. Loket pasien umum/pihak ketiga/SKTM berjumlah 1 loket.

Data kunjungan pasien menunjukkan bahwa pasien di RSUD dr. Doris Sylvanus didominasi oleh pasien peserta JKN-KIS sebagaimana disajikan pada Tabel 1.
Tabel 1 Jumlah kunjungan pasien tahun 2019

\begin{tabular}{clcc}
\hline \multirow{2}{*}{ No } & \multirow{2}{*}{ Jenis Perawatan } & \multicolumn{2}{c}{ Jenis Pasien } \\
& & Umum & \multicolumn{1}{c}{ JKN } \\
\hline 1 & Rawat Jalan & 15.144 & 90.445 \\
2 & Rawat Inap & 2.201 & 20.427 \\
\hline \multirow{2}{*}{} & Jumlah & $\mathbf{1 7 . 3 4 5}$ & $\mathbf{1 1 8 . 8 7 2}$ \\
\hline
\end{tabular}

Persyaratan pendaftaran pasien peserta JKN-KIS hanya perlu membawa kartu JKN-KIS serta surat rujukan dari fasilitas kesehatan tingkat pertama (FKTP) sesuai dengan yang tertera pada kartu. Terkecuali bagi pasien gawat darurat dapat langsung dilayani tanpa surat rujukan. Sebelumnya peserta diharuskan membawa persyaratan tambahan seperti fotocopy berkas Kartu Tanda Penduduk (KTP) dan Kartu Keluarga (KK) untuk mendaftar, hal ini dianggap menyulitkan karena terkadang pasien lupa membawa berkas tersebut sehingga dinilai mempersulit pelayanan. Maka dari itu dengan hanya membawa kartu JKN-KIS merupakan salah satu pemenuhan hak pasien dalam pelayanan kesehatan yaitu memberikan pelayanan yang efektif dan efisien kepada pasien peserta JKN-KIS untuk mendapatkan pelayanan kesehatan. Selanjunya dalam hal ketersediaan ruang rawat inap di RSUD dr. Doris Sylvanus saat ini sudah memadai dan pihak rumah sakit selalu berupaya untuk tetap melayani apabila ada ruangan rawat inap yang penuh. Oleh sebab itu tidak ada ditemukan pasien peserta JKN-KIS yang ditolak pelayanannya.

Sistem pada BPJS Kesehatan terbagi menjadi tiga kelas perawatan yang diatur dalam Peraturan BPJS Kesehatan No 1 Tahun 2014 tentang Penyelenggaraan Jaminan Sosial Kesehatan. Peserta tiga kelas perawatan BPJS Kesehatan mendapatkan layanan yang sama dalam skema manfaatnya, seperti dokter, pemeriksaan, pengobatan, obat, konsultasi dokter spesialis, hingga pemeriksaan laboratorium. Perbedaan dari kelas I, II, dan III BPJS Kesehatan hanya pada fasilitas ruang inapnya (Firdaus dan Windabio, 2019).

RSUD dr. Doris Sylvanus dalam memberikan pelayanan kesehatan selalu berpegang pada misi dan visi rumah sakit yaitu untuk selalu meningkatkan pelayanan yang bermutu dan prima terutama dalam hal kepuasan pasien. Kepuasan pasien adalah suatu tingkat perasaan pasien yang timbul sebagai akibat dari kinerja pelayanan kesehatan yang diperoleh setelah pasien membandingkan apa yang diharapkannya. Dari definisi tersebut menerangkan apabila harapan pasien terhadap rumah sakit terpenuhi, maka pelayanan dapat dikatakan baik. Sedangkan apabila harapan pasien tidak terpenuhi makan pelayanan dikatakan buruk.

Kepuasaan pengguna jasa pelayanan kesehatan dipengaruhi oleh beberapa faktor yaitu:

1. Pemahaman pengguna jasa tentang jenis pelayanan yang akan diterimanya. Dalam hal ini aspek komunikasi memegang peranan penting 
2. Empati (sikap peduli) yang ditunjukkan oleh petugas kesehatan. Sikap ini akan menyentuh emosi pasien. Faktor ini akan berpengaruh pada tingkat kepatuhan pasien

3. Biaya. Biaya yang mahal akan memberatkan pasien dan keluarganya

4. Penampilan fisik petugas, kondisi kebersihan dan kenyamanan ruangan

5. Jaminan keamanan yang ditunjukkan oleh petugas kesehatan. Ketepatan jadwal pemeriksaan dan kunjungan dokter juga termasuk pada faktor ini

6. Keandalan dan keterampilan petugas dalam memberi layanan kesehatan

7. Kecepatan petugas dalam memberi tanggapan terhadap keluhan pasien.

Hasil survei kepuasan pasien yang dilakukan selama bulan September 2019 menunjukkan bahwa RSUD dr. Doris Sylvanus masuk dalam kategori baik. Indikator survei kepuasan pasien yang terdiri dari:

1. Persyaratan pelayanan

2. Prosedur pelayanan

3. Waktu Pelayanan

4. Biaya Tarif

5. Produk layanan

6. Kompetensi pelaksana

7. Perilaku pelaksana

8. Penanganan pengaduan saran dan masukan

9. Sarana dan prasarana.

Hasil perhitungan Indeks Kepuasan Maskyarakat (IKM) terhadap pelayanan kesehatan di RSUD dr. Doris Sylvanus bernilai total 80. Dari hasil survei kepuasan pasien itulah kiranya dapat memberikan masukan kepada pihak RSUD dr. Doris Sylvanus untuk terus berbenah dalam memberikan pelayanan kesehatan kepada semua pasien yang ingin berobat ke rumah sakit supaya pelaksanaan pelayanan kesehatan selalu terlaksana dengan baik dan optimal.

RSUD dr. Doris Sylvanus berusaha sebaik mungkin dalam memberi pelayanan kesehatan yang nyaman dan aman bagi semua pasien. Jika pasien merasa ada haknya yang kurang terpenuhi dapat mengadukan keluhannya pada pusat penanganan pengaduan dan informasi (PPIP) bagian humas RSUD dr. Doris Sylvanus. Hal ini merupakan salah satu pemenuhan hak pasien yang dilindungi yaitu untuk dapat mengajukan pengaduan atas kualitas pelayanan yang diberikan oleh rumah sakit dan menajukan usul, saran, perbaikan atas perlakuan rumah sakit terhadap dirinya.

Penanganan keluhan merupakan salah satu instrumen untuk menyelesaikan masalah pelayanan kesehatan, baik yang bersifat administratif maupun bersifat medis. Permasalahan bisa terjadi antara Peserta dengan Fasilitas Kesehatan; antara Peserta dengan BPJS Kesehatan; antara BPJS Kesehatan dengan Fasilitas Kesehatan; atau antara BPJS Kesehatan dengan Asosiasi Fasilitas Kesehatan.
Selama tahun 2018 terdapat beberapa pengaduan yang masuk dari pasien di RSUD dr. Doris Sylvanus sebagaimana disajikan pada Tabel 2.

Tabel 2 Rekapitulasi pengaduan di RSUD dr. Doris Sylvanus tahun 2018

\begin{tabular}{|c|c|}
\hline Keterangan & Jumlah \\
\hline \multicolumn{2}{|l|}{ A. Bagian/Bidang } \\
\hline 1. Rawat inap & 10 \\
\hline 2. Rawat jalan & 6 \\
\hline 3. Surat kaleng & 1 \\
\hline 4. Loket penerimaan pasien & 4 \\
\hline 5. Satpam & 3 \\
\hline 6. Laboratorium & 1 \\
\hline 7. Parkir & 2 \\
\hline 8. Apotik & 2 \\
\hline \multirow[t]{2}{*}{ 9. Verifikasi } & 1 \\
\hline & 30 \\
\hline \multicolumn{2}{|l|}{ B. Cara Pengaduan } \\
\hline 1. SMS pengaduan & 14 \\
\hline 2. Keluhan langsung & 14 \\
\hline 3. Surat kaleng & 1 \\
\hline \multirow[t]{2}{*}{ 4. WhatsApp } & 1 \\
\hline & 30 \\
\hline \multicolumn{2}{|l|}{ C. Jenis Pelayanan } \\
\hline Medis & 19 \\
\hline Non medis & 11 \\
\hline & 30 \\
\hline
\end{tabular}

RSUD dr. Doris Sylvanus memberikan kebebasan bagi pasien dalam menyampaikan keluhannya karena itu merupakan hak pasien yang dilindungi yaitu dengan cara sebagai berikut:

a. Menyediakan informasi tentang kebijakan dan sistem pelayanan kesehatan di rumah sakit.

b. Melakukan verifikasi terhadap keluhan.

c. Menangani masalah keluhan dengan cepat dan transparan.

Adapun prosedur pengaduan terkait pelayan di RSUD dr. Doris Sylvanus yaitu sebagai berikut:

a. Menerima kritik, saran dan keluhan melalui kotak saran.

b. Mengidentifikasi keluhan.

c. Menindaklanjuti /merespon keluhan secara langsung ke unit yang dituju.

d. Melakukan pengawasan terhadap unit yang mendapat keluhan dari pasien.

\subsection{Hambatan Pelaksanaan Perlindungan Hukum Terhadap Pasien JKN-KIS}

Pemerintah Indonesia berkomitmen agar mencapai UHC (Universal Health Coverage) sehingga seluruh masyarakat dapat memiliki akses mendapatkan pelayanan kesehatan. UHC merupakan sistem kesehatan yang 
memastikan setiap warga memiliki akses yang adil terhadap pelayanan kesehatan promotif, preventif, kuratif, dan rehabilitatif yang bermutu dengan biaya terjangkau (Mainita, 2018). UHC mengandung dua elemen inti yakni akses pelayanan kesehatan yang adil dan bermutu bagi setiap warga, dan perlindungan resiko finansial ketika warga menggunakan pelayanan kesehatan.

Pelayanan BPJS Kesehatan di fisilitas kesehatan memang selalu ada ketidakpuasan dari pasien, berdasarkan data keluhan peserta JKN-KIS terhadap layanan di Faskes tahun 2016 sebagai berikut:

1. Antrian pelayanan di Faskes, peserta tidak dilayani dokter, obat kosong

2. Iuran biaya

3. FKRTL membuat kuota pelayanan peserta

4. Pembatasan pemberian obat, ketersediaan obat

5. Pasien disuruh datang berulang-ulang

6. Jam praktek dokter tidak sesuai

7. Kurang adanya informasi mengenai jenis pelayanan yang ada di rumah sakit

8. Adanya kuota rawat inap, informasi ketersediaan kamar hanya $10 \%$ dari total rumah sakit

9. Keterbatasan ketersediaan ruang rawat intensif.

Sedangkan keluhan Fasilitas kesehatan terhadap BPJS Kesehatan pada tahun 2016 sebagai berikut:

1. Distribusi Peserta di FKTP tidak merata, Peserta banyak terdaftar di Faskes tertentu

2. Obat kosong di Distributor

3. Proses pengajuan klaim lama

4. Proses Kerja Sama Faskes tidak transparan

5. Pasien tidak memahami prosedur pelayanan

6. Tarif Kapitasi dan INACBG kurang memadai

7. Terlalu banyak aplikasi yang harus dientri.

Hasil dari penelitian yang telah dilakukan peneliti sendiri di RSUD dr. Doris Sylvanus terdapat beberapa hambatan pelaksanaan perlindungan hukum terhadap pasien peserta JKN-KIS dalam mendapatkan pelayanan kesehatan di RSUD dr. Doris Sylvanus Palangka Raya yaitu:

1. Kepatuhan peserta JKN-KIS membayar iuran

Kurang patuhnya peserta JKN-KIS melaksanakan kewajibannya membayar iuran tepat waktu sehingga pasien tidak dapat mengunakan haknya untuk mendapatkan pelayanan. Hal ini dapat dilihat dari masih banyak pasien peserta JKN-KIS yang menunggak iuran dan membayar iuran hanya saat menderita sakit saja (Tabel 3).

Berdasarkan data tersebut yang diperoleh dari kantor BPJS Kesehatan cabang Palangka Raya terkait jumlah piutang peserta JKN-KIS sampai awal bulan September 2019 berjumlah Rp 54.556.089.149; dan tagihan BPJS Kesehatan cabang Palangka Raya ke RSUD dr. Doris Sylvanus mencapai Rp 67.145.707.673.

2. Alur pelayanan yang tidak dipahami peserta JKN-KIS Prosedur pelayanan di fasilitas kesehatan rujukan tingkat lanjutan (FKRTL) yang tidak diketahui oleh pasien
Tabel 3 Tunggakan iuran peserta BPJS JKN-KIS (Agustus 2019)

\begin{tabular}{clr} 
No. & \multicolumn{1}{c}{ Kab/Kota } & Piutang (Rp) \\
\hline 1 & Kota Palangka Raya & 19.475 .759 .306 \\
2 & Kab. Kapuas & 14.502 .923 .452 \\
3 & Kab. Gunung Mas & 8.449 .075 .185 \\
4 & Kab. Katingan & 6.081 .258 .740 \\
5 & Kab. Pulang Pisau & 6.047 .072 .466 \\
\hline & TOTAL & $\mathbf{5 4 . 5 5 6 . 0 8 9 . 1 4 9}$ \\
\hline
\end{tabular}

peserta JKN-KIS seperti harus adanya surat rujukan dari fasilitas kesehatan tingkat pertama (FKTP) dan surat rujukan pasien yang sudah habis masa berlakunya.

Merujuk Undang-Undang Nomor 24 Tahun 2011 tentang Badan Penyelenggara Jaminan Sosial (BPJS), fasilitas kesehatan tingkat pertama dan tingkat lanjutan wajib melakukan sistem rujukan dengan mengacu pada peraturan perundangundangan yang berlaku dalam menjalankan pelayanan kesehatan.

Disebutkan pula bahwa, peserta yang ingin mendapatkan pelayanan yang tidak sesuai dengan sistem rujukan dapat dimasukkan dalam kategori pelayanan yang tidak sesuai dengan prosedur. Sehingga peserta tidak dapat dibayarkan oleh BPJS Kesehatan.

3. Standar waktu pelayanan

Waktu tunggu antrian pada loket rawat jalan untuk mendapatkan pelayanan kesehatan relatif lama melebihi satu jam pelayanan, hal ini masih dikeluhkan sebagian pasien peserta JKN-KIS yang merasa pelayanan kepada mereka kurang cepat karena melebihi standar waktu pelayanan.

Standar pelayanan yaitu waktu yang dibutuhkan mulai dari pasien mendaftar antrian di loket petugas pembuat eligibitas untuk mendapat nomor eligibitas (SEP) lalu pasien dilayani oleh dokter sesuai dengan indikasi medis sesuai pada surat rujukan dari fasilitas kesehatan tingkat pertama (FKTP) sampai pasien selesai dilayani, hal ini disebabkan beberapa hal seperti menunggu hasil pemeriksaan penunjang (rontgen, laboratorium, lainlain), menunggu dokter yang masih melakukan pemeriksaan pada pasien yang di rawat inap.

4. Sarana dan Prasarana

Pihak RSUD dr. Doris Sylvanus menyatakan sudah menyediakan sarana dan prasarana yang memadai bagi pasien maupun pengunjung yang berada di rumah sakit, tetapi masih ada yang kurang terutama dokter sub spesialis, karena masih belum tersedianya sebagian sub spesialis tenaga kesehatan yang ada di rumah sakit sehingga pasien dengan penyakit tertentu perlu dirujuk ke fasilitas kesehatan tingkat lanjut (Banjarmasin, Surabaya).

Pihak terkait yang diwawancari mengatakan ada wacana bahwa pemerintah provinsi Kalimnatan Tengah 
ingin membangun rumah sakit tipe $A$ sebagai solusi serta jawaban bagi kebutuhan kesehatan masyarakat terhadap pelayanan kesehatan di Palangka Raya sehingga pasien tidak perlu dirujuk keluar daerah.
3. Pihak pasien sebagai penerima jasa pelayanan kesehatan agar dapat mendukung program JKN-KIS salah satunya melaksanakan kewajibannya untuk membayar iuran karena sifatnya gotong royong yaitu yang sehat membantu yang sakit sehingga program ini dapat terus berjalan.

\section{PENUTUP}

Berdasarkan hasil penelitian dan pembahasan sebagaimana telah diuraikan, dapat diambil kesimpulan sebagai berikut:

1. Pelaksanaan perlindungan hukum terhadap pasien JKNKIS BPJS Kesehatan di RSUD dr Doris Sylvanus sudah sesuai peraturan perundangan-undangan yang berlaku dengan tingkat kepuasan masyarakat dalam kategori baik. Hal ini dibuktikan dengan terpenuhinya informasi mengenai tata tertib dan peraturan di rumah sakit, informasi hak dan kewajiban pasien, informasi diagnosis dan tatacara tindakan medis dari tenaga kesehatan, mendapat jaminan keamanan dan keselamatan selama di rumah sakit serta adanya tempat penanganan keluhan dan pengaduan pasien yang disediakan pihak rumah sakit. Penangan keluhan dan pengaduan pasien tersebut dengan mengutamakan musyawarah sebagai penyelesaiannya.

2. Hambatan pelaksanaan perlindungan hukum terhadap pasien JKN-KIS BPJS Kesehatan di RSUD dr Doris Sylvanus yaitu: pasien peserta JKN-KIS tidak melaksanakan kewajibannya yaitu membayar iuran tepat waktu sehingga tidak dapat menggunakan manfaat dari JKN-KIS, pasien peserta JKN-KIS tidak mengetahui prosedur pelayanan BPJS Kesehatan di rumah sakit seperti tidak membawa surat rujukan dari fasilitas kesehatan tingkat pertama (FKTP), standar waktu mendapatkan pelayanan kesehatan masih relatif lama dan belum tersedianya sebagian sub spesialis tenaga kesehatan yang ada di rumah sakit sehingga pasien dengan penyakit tertentu perlu dirujuk ke fasilitas kesehatan tingkat lanjut di luar daerah.

Berdasarkan kesimpulan di atas, saran-saran yang dapat diberikan kepada masing-masing pihak baik itu pasien, rumah sakit, dan BPJS kesehatan adalah sebagai berikut:

1. Pihak rumah sakit sebagai pemberi pelayanan kesehatan agar dapat meningkatkan kualitas pelayanan lebih baik lagi terutama dalam hal manajemen koordinasi untuk efisiensi, komunikasi dan informasi kepada masyarakat dan memberlakukan layanan pendaftaran online di rumah sakit terintergrasi sehingga pasien mendapatkan kepastian jadwal/ kunjungan dokter (mengurangi waktu tunggu/ kepastian jadwal dokter).

2. Pihak BPJS kesehatan sebagai penyelenggara program JKN-KIS agar dapat mensosialisaikan dan meningkatkan pelayanan program kesehatan tersebut sehingga seluruh masyarakat terlindungi dan merasakan manfaat dari JKN-KIS.

\section{DAFTAR PUSTAKA}

Anita, B., \& Febriawati, H. (2019). Puskesmas dan Jaminan Kesehatan Nasional. Yogyakarta. Deepublish.

Ainsyiyah, E. D., Suhaidi, S., Barus, U. M., \& Ikhsan, E. (2015). Perlindungan Hukum Bagi Pasien Pengguna Jamkesmas dalam Pelayanan Kesehatan di RSUD DR. RM. Djoelham Binjai Terkait Berlakunya BPJS di Bidang Kesehatan. USU Law Journal, 3(3), 151-160.

Dewi, R. S. (2020). Perlindungan Hukum terhadap Peserta BPJS Kesehatan dalam Pelayanan kesehatan di rumah sakit. Focus hukum upmi, 1(2), 74-79.

Firdaus, K. K., \& Wondabio, L. S. (2019). Analisis Iuran dan Beban Kesehatan dalam Rangka Evaluasi Program Jaminan Kesehatan. Jurnal ASET (Akuntansi Riset), 11(1), 147-158.

Ginting, D. (2019). Kebijakan Penunjang Medis Rumah Sakit (SNARS). Yogyakarta. Deepublish.

Jabbar, L. D. A. A. A. (2020). Pertanggung Jawaban BPJS Kesehatan terhadap Pelayanan Asuransi Kesehatan Masyarakat. Jurist-Diction, 3(2), 387-400.

Mainita, M. (2018). Tanggung Jawab Negara Terhadap Pelaksanaan Jaminan Kesehatan Dalam Mewujudkan Universal Health Coverage. Jurnal Hukum dan Keadilan MEDIASI, 8(1), 1-18.

Mulia, D. S. (2017). Tingkat Kepuasan Pasien Umum Rawat Jalan terhadap Kualitas Pelayanan Instalasi Farmasi RSUD Dr. Doris Sylvanus Palangka Raya. Jurnal Surya Medika (JSM), 2(2), 40-48.

Muninjaya, A. G. (2004). Manajemen buku kesehatan. Jakarta: Penerbit Buku Kedokteran EGC.

Nanda, A., \& Aminah, S. (2016). Perlindungan Hukum terhadap Pasien Bpjs Kesehatan di Rsup Dr. Soeradji Tirtonegoro Klaten. Diponegoro Law Journal, 5(4), 1-18.

Siswati, S. (2013). Etika dan Hukum Kesehatan: Dalam Perspektif Undang-Undang Kesehatan.

Susila, G. P. A. J. (2014). Implementasi Quality Function Deployment (QFD) untuk Meningkatkan Layanan Publik di RSUD Kabupaten Buleleng Bali. Jurnal Ilmu Sosial dan Humaniora, 3(2), 396-409.

Suprianto, A., \& Mutiarin, D. (2017). Evaluasi Pelaksanaan Jaminan Kesehatan Nasional. Journal of Governance and Public Policy, 4(1), 71-107.

Setyawan, F. E. B. (2018). Sistem Pembiayaan Kesehatan. Magna Medica: Berkala Ilmiah Kedokteran dan Kesehatan, 2(4), 57-70.

Soekidjo, N. (2010). Etika dan hukum kesehatan. Jakarta: Rineka Cipta. 
Waluyo, B. (2002). Penelitian Hukum Dalam Praktek, Jakarta. Sinar Grafika.

Yustina, E. W. (2012). Mengenal Hukum Rumah Sakit. Keni Media.

Undang-Undang Dasar Negara Republik Indonesia Tahun 1945.

Undang-Undang Nomor 44 Tahun 2009 tentang Rumah Sakit.

Undang-Undang Nomor 36 Tahun 2009 tentang Kesehatan.
Undang-Undang Nomor 40 Tahun 2004 tentang Sistem Jaminan Sosial Nasoinal.

Undang-Undang Nomor 24 Tahun 2011 tentang Badan Penyelenggara Jaminan Sosial.

Peraturan Badan Penyelenggara Jaminan Sosial Kesehatan Nomor 1 Tahun 2014 tentang Penyelenggaraan Jaminan Kesehatan.

Peraturan Menteri Kesehatan Nomor 71 Tahun 2013 tentang Pelayanan Kesehatan Pada Jaminan Kesehatan Nasional. 